\title{
Trilha sonora de cinema: uma análise sobre os filmes tropa de elite 1 e 2*
}

\section{Cinema soundtrack: an analysis about the Elite Squad films 1 and 2}

\author{
Cleber Fernando Gomes ${ }^{1}$ \\ Universidade Federal de São Paulo - UNIFESP
}

\section{Resumo}

Esta pesquisa abre uma discussão sobre a trilha sonora dos filmes Tropa de Elite $1 \mathrm{e}$ 2, dirigido pelo cineasta brasileiro José Padilha nos anos de 2007 e 2010, respectivamente. Desse modo, ressaltamos que a trilha sonora composta para os filmes, é um objeto de estudo importante, uma vez que o seu conteúdo crítico e político consegue atingir uma enorme quantidade de pessoas por meio da indústria cultural. Por meio de metodologia histórica e bibliográfica, concluímos que a trilha sonora dos dois filmes constrói uma expressão crítica através da arte da música e do cinema, sobre os graves problemas sociais, políticos e econômicos localizados na cidade do Rio de Janeiro.

Palavras-chave: trilha sonora, cinema, Brasil, cultura

\section{Abstract}

This research opens up a discussion on the soundtrack of the films Elite Squad 1 and 2, directed by Brazilian filmmaker José Padilha in 2007 and 2010, respectively. Thus, we emphasize that the soundtrack composed for these films is an important object of study, since its critical and political content can reach a huge amount of people through cultural industry. Through historical and bibliographical methodology, we conclude that the soundtrack of these two films builds a critical expression through

\footnotetext{
* Esta pesquisa foi apresentada como conclusão do curso de Música, Cultura y Poder do Consejo Latinoamericano de Ciencias Sociales - CLACSO/Argentina, 2014, sob orientação do Prof. Dr. Ángel G. Quintero Rivera, do Centro de Investigaciones Sociales da Universidad de Puerto Rico - CIS/UPR. Pesquisa apresentada também, por meio de comunicação oral, na II Jornada de Sociologia Política da Universidade Vila Velha - UVV/2015.
}

Revista Digital do LAV - Santa Maria - vol. 8, n. 3, p. 3 - 27. - set./dez. 2015 ISSN 1983 - 7348 http://dx.doi.org/10.5902/1983734818109 
the art of music and cinema, about the serious social, political and economic problems located in the city of Rio de Janeiro.

Keywords: soundtrack, cinema, Brazil, culture

\section{Introdução}

A obra cinematográfica é composta de diversos elementos audiovisuais que dialogam simultaneamente contribuindo para contar uma história ficcional ou documental. Nesse caso, a música no cinema é um elemento essencial porque tem o poder de transformar uma cena em algo impactante ou singelo. A imagem do cinema se funde com sons que definirá uma ação dando a cena um realismo impressionante. Segundo Carrasco (2003, p.126) "a sincronia entre sons e imagens abria ao cinema o universo sonoro em toda a sua riqueza e multiplicidade".

Com o surgimento do cinema sonoro na década de 1920 pelo sistema Vitaphone da Warner Brothers nos Estados Unidos da América (EUA), a música no cinema passa ser algo primordial e necessário para desenvolver narrativas com mais apelo sentimental e comercial. A partir da indústria hollywoodiana a música no cinema foi difundida rapidamente pelo mundo, e o fenômeno não demora a chegar ao Brasil que também se valeu da mesma tecnologia para produzir seus filmes. Sobre o fato histórico do cinema sonoro, Rivera (2009, p.139), destaca que "el surgimiento del cine sonoro en Latinoamerica estuvo indisolublemente vinculado a su música y la emergente espectacularidad bailable de lo tropical".

A tecnologia no século XX, após a segunda Guerra Mundial, evoluiu rapidamente principalmente pelos altíssimos investimentos dos EUA em educação e ciência o que impactou numa profunda transformação social, e consequentemente, cinematográfica. Essa evolução em Ciência e Tecnologia (C\&T) fez com que diversos setores da sociedade obtivessem êxitos nas suas produções, e as artes audiovisuais também foram beneficiadas. Segundo Trigueiro (2009, p.49) "ciência e tecnologia cumprem importante papel no desenvolvimento histórico-social e no avanço das forças produtivas".

Para pensarmos a música no cinema brasileiro não podemos esquecer-nos de refletir sobre esses fenômenos tecnológicos e científicos que marcaram a história de diversas sociedades, inclusive a brasileira. No caso específico do Brasil, é interessante

Revista Digital do LAV - Santa Maria - vol. 8, n. 3, p. 3 - 27. - set./dez. 2015 ISSN 1983 - 7348 http://dx.doi.org/10.5902/1983734818109 
pontuar que sempre houve um atraso no desenvolvimento de C\&T, principalmente por ser um país da América do Sul considerado subdesenvolvido.

Porém, vale lembrar que mesmo com todas as dificuldades econômicas e políticas vivenciadas pelo Brasil na área de $C \& T$, o país sempre recebeu em tempo recorde as inovações do setor cinematográfico, como podemos observar na história de suas produções fílmicas. Esse fenômeno de receber as inovações rapidamente, se dava pelo fato do grande número de imigrantes vivendo no Brasil e que faziam intercâmbios entre EUA e países da Europa, trazendo materiais e técnicas cinematográficas de suas viagens internacionais.

Após a implantação do Plano Real na década de 1990, o Brasil tem um novo projeto econômico que vai beneficiar a retomada do cinema nacional e a produção cinematográfica ganhará novo fôlego. Mas é com a criação da Globo Filmes que o cinema brasileiro vai conseguir maior visibilidade no mercado cinematográfico conseguindo produzir e distribuir seus filmes. Com ajuda das Organizações Globo proprietária de diversos meios de comunicação no país - o cinema da retomada consegue atingir índices de bilheterias satisfatórios com alguns sucessos nacionais.

No século XXI, a Globo Filmes, com toda a sua estrutura organizacional consegue visibilizar o cinema nacional com o sucesso de alguns filmes que fizeram história nas bilheterias do país. Nesse caso, os filmes Tropa de Elite 1 (2007) e Tropa de Elite 2 (2010), fazem parte desse fenômeno cinematográfico e comercial. Observamos que esses dois filmes são produtos da indústria cultural e que "o significado de uma imagem pode ser reforçado pelo diálogo e pela música que a acompanha" (SANTAELLA, 2005, p.12).

Portanto, refletir sobre o cinema contemporâneo seria impossível se não levarmos em consideração a música vinculada as suas imagem-movimento. A música no cinema exerce um poder sobre a narrativa, construindo e desconstruindo ideologias, causando emoções e desespero, num público espectador que não é só visual, mas audiovisual.

\section{Música no cinema}

A música no cinema começa a ganhar espaço na década de 1920, quando nos EUA a indústria cinematográfica, por meios de experimentos científicos e tecnológicos, lançam novos equipamentos com objetivos de alcançar projeções fílmicas sonoras. Antes da junção sonora no mesmo suporte do filme, o cinema já 
era acompanhado por música, tocadas no ambiente da sala de exibição, na sua maioria por pianistas.

Em Máximo (2003, p.10, apud, Hanns Eisler) observamos que "desde o começo os filmes têm sido acompanhados por música", e tinham como objetivos neutralizar os efeitos impactantes que as imagens causavam nos espectadores.

A função mágica da música era afugentar os espíritos do mal que as pessoas inconscientemente temiam. A música começou a ser empregada como antídoto da imagem. Era necessária para livrar o espectador do incômodo de ver figuras de gente agindo, representando ou mesmo movendo os lábios como se falassem, mas em silêncio. $O$ fato de essas figuras serem vivas e não-vivas ao mesmo tempo é que constituía o seu caráter fantasmagórico. A música surgiu não para dar-lhes vida (...) mas para exorcizar o medo ou ajudar o espectador a absorvêlo (MÁXIMO, 2003, p.10, apud, Hanns Eisler).

Dentro desse contexto, a música surge no cinema como forma de aliviar o estranhamento causado pela imagem-movimento. Aquele que seria um invento moderno ao seu tempo - assim como a fotografia que congelava a imagem assustava a maioria das pessoas com o poder de sua câmera.

Entretanto, não demorou para que o invento cinematográfico aliado ao poder da música instrumental e posteriormente vocal, conseguisse despertar e atrair a atenção das pessoas e consequentemente tornar-se um fenômeno social que transformou e ainda continua transformando a vida em sociedade.

A música no cinema ganha uma força extraordinária com a chegada à Hollywood do compositor vienense Max Steiner que com sua capacidade criativa conseguiu inserir na sétima arte uma ilusão audiovisual potencializando os efeitos fantásticos produzidos pelo cinema. Com as músicas instrumentalizadas de Max Steiner, o cinema transformou-se em algo sensorial e grandioso, uma vez que eleva os sentidos cênicos dando maior dramaticidade e significando afetivamente os filmes, que para Rodríguez (2006, p.319) "la música como forma de comunicación entre los hombres - en tanto es capaz de plasmar imágenes y reforzar mensajes e ideas".

Portanto, analisar o caso específico de Max Steiner no cinema hollywoodiano é interessante porque esse compositor austríaco conseguiu imprimir sua marca em filmes clássicos do cinema norte-americano, que ultrapassou fronteiras sendo reconhecido e admirado em diversos países. Max Steiner não só potencializou o cinema de Hollywood com suas músicas, como também contribuiu para fortalecer a difusão dos filmes norte-americanos pelo mundo, o que resultou em ações

Revista Digital do LAV - Santa Maria - vol. 8, n. 3, p. 3 - 27. - set./dez. 2015 ISSN 1983 - 7348 http://dx.doi.org/10.5902/1983734818109 
estratégicas para aumentar os lucros dos estúdios Warner Brothers, local onde o compositor trabalhou por muito tempo, dedicando-se quase que exclusivamente a musicar os filmes deste estúdio nos EUA.

As técnicas do leitmotiv, do mickeymousing, e do source music, utilizadas por Max Steiner, foram recursos que o compositor usufruiu para prender atenção dos espectadores e que contribuíram para tornar muitos dos filmes musicados pelo austríaco, um blockbuster.

O exemplo que citamos referente às músicas do cinema norte-americano se fez necessário porque é um produto globalizado que influencia sociedades de diversos países, interferindo e transformando suas culturas, economia e política.

Porém, não podemos deixar de citar o sucesso do maestro italiano Ennio Morricone que trabalhou na trilha sonora de mais de 500 filmes. Morricone também foi o responsável pela trilha sonora de diversos filmes políticos produzidos na década de 1970 na Itália, sendo um dos compositores mais conscientes e atuantes politicamente, por meio da música de cinema. Um dos grandes triunfos do maestro Morricone foi produzir a trilha sonora do filme "A Fistful of Dollars" em 1964:

Sua trilha sonora alcançou sucesso paralelo ao do filme e o compacto com o tema principal foi um dos mais vendidos na febre pop italiana dos anos de 1960. Sem apelar à tradição "cavalheiresca" do western americano, a música de Morricone orientou-se à estilização e criou uma nova estética para o gênero com sua referência mexicana nos trompetes mariachi, com os solitários assobios, ritmos em sugestão de cavalgada, marchas fúnebres (Theme From Fistful of Dollars) e até influência medieval, como em Square Dance ou a flauta doce de Titoli, que se adequavam exemplarmente à crueza plástica da fita. A faixa Fistful of Dollars Suite é uma montagem contínua (12 minutos) que combina os temas da trilha em sequência diferente (MARTINO, 2008, p.160).

Observamos que a música de cinema na Itália também teve grande importância na área artística, econômica e política. Ennio Morricone conseguiu através de seus arranjos e composições construir uma história musical na cinematografia italiana, imprimindo sua característica popular aos filmes daquele país.

Portanto, é o cinema norte-americano (Hollywood) que acaba se tornando referência técnica para muitos cineastas por ser um cinema de sucesso global que consegue atingir milhões de pessoas. Observamos que nos filmes brasileiros Tropa

Revista Digital do LAV - Santa Maria - vol. 8, n. 3, p. 3 - 27. - set./dez. 2015 ISSN 1983 - 7348 http://dx.doi.org/10.5902/1983734818109 
de Elite 1 e 2, o diretor José Padilha faz uso de muitas dessas técnicas hollywoodianas e consegue com seus dois filmes causar grande impacto na cultura cinematográfica brasileira, além de levantar diversos debates acerca da temática que o filme se propôs a tratar. Destacamos que a trilha sonora dos filmes de José Padilha foram construídas com forte apelo social e crítico aos problemas enfrentados pela população da cidade do Rio de Janeiro, cenário dos dois filmes.

\section{Tropa de elite 1 e 2}

Os filmes dirigidos por José Padilha tiveram uma grande repercussão no mundo cinematográfico. No Brasil e no mundo Tropa de Elite foi objeto de elogios e críticas. Ao tratar sobre a violência e os problemas sociais vivenciados pela população da cidade do Rio de Janeiro, o diretor do filme conseguiu abrir uma discussão sobre quais os limites, deveres e direitos das forças do poder público, e consequentemente a isso, construiu no filme situações complexas em que vivem as pessoas nas favelas da cidade, sob conflitos entre traficantes.

Os filmes têm como protagonista o Batalhão de Operações Policiais Especiais (BOPE), da Polícia Militar do Estado do Rio de Janeiro (PMERJ). A narrativa central concentra-se no combate a criminalidade existente nas favelas da cidade carioca, principalmente derivadas do narcotráfico. A partir dessa realidade, a trilha sonora dos filmes também foram construídas com foco nas questões da violência, do crime organizado, da discriminação, da opressão, da corrupção, o bem e o mau, a política, a polícia e o social, etc. Nas tabelas 1 e 2, observamos relação das músicas que fizeram parte da trilha sonora dos dois filmes:

Tabela 1: Músicas dos Filmes Tropa de Elite 1 e 2.

\begin{tabular}{ll}
\hline Música & Interpretadas por: \\
\hline Rap das Armas & Mc Júnior \& Mc Leonardo \\
Tropa de Elite & Tihuana \\
Rap da Felicidade & Mc Cidinho \& Mc Doca \\
Brilhar a Minha Estrela & Sangue da Cidade \\
Kátia Flávia & Fausto Fawcett \& os Robôs Efêmeros \\
Polícia & Titãs \\
Lado B Lado A & O Rappa \\
Andando pela África & Barbatuques (percussão corporal) \\
Nossa Bandeira & Mc Júnior \& Mc Leonardo \\
\hline
\end{tabular}

Revista Digital do LAV - Santa Maria - vol. 8, n. 3, p. 3 - 27. - set./dez. $2015 \quad$ ISSN 1983 - 7348 http://dx.doi.org/10.5902/1983734818109 


\begin{tabular}{ll}
\hline O Calibre & Os Paralamas do Sucesso \\
Que País é Esse? & Legião Urbana \\
Tribunal de Rua & O Rappa \\
Candidato Caô Caô & Marcelo D2 \\
Quem é Ela? & Zeca Pagodinho \\
Comboio do Terror & Tihuana \\
Tá Tudo Errado & Mc Júnior \& Mc Leonardo \\
Zé do Caroço & Leci Brandão \\
Brasil & Cazuza
\end{tabular}

Fonte: CD Trilha Sonora dos Filmes Tropa de Elite 1 e 2 (2007; 2010).

Tabela 2: Músicas dos Filmes Tropa de Elite 1 e 2 Instrumentadas por Pedro Bromfman.

\begin{tabular}{c}
\hline Músicas \\
Invasão do BOPE \\
O plano \\
Treinamento pra guerra \\
Passa que é teu \\
Nascimento sem saída \\
Brasília \\
Invasão na favela \\
Tiroteio e hospital \\
Filho
\end{tabular}

Disponível em: http://www.pedrobromfman.com/home.php

Na tabela 2 observamos uma relação de músicas instrumentalizadas que fazem parte dos dois filmes Tropa de Elite. Essas músicas foram desenvolvidas pelo compositor Pedro Bromfman, experiente na criação de trilhas sonoras e músicas incidentais para cinema. Sendo assim, notamos o uso de diversos instrumentos, dando maior realismo às cenas de ação e suspense. Os artifícios do samba 
instrumental é audível na música "O Plano", onde há uma mistura de guitarra com cuíca e alguns instrumentos de percussão.

As músicas instrumentais dos filmes (ou temas incidentais), sonorizam um contexto ficcional construindo o Rio de Janeiro através de uma história dramática e cheia de emoções. Para agregar valor às essas cenas o compositor não economizou no uso dos instrumentos de cordas, percussão e sopro. Na música "Filho" verificamos a utilização de instrumentos de cordas que vão dar maior dramaticidade e emoção a cena. Dessa forma, as músicas instrumentalizadas - ou incidentais - contribuem para contar uma história e é essencial na construção narrativa cinematográfica.

Entretanto, as músicas descritas na tabela 1 apresentam letras enfatizando os problemas sociais e políticos existentes no Brasil. Com exceção ao samba "Quem é ela?", cantado por Zeca Pagodinho, todas as outras músicas tem uma letra crítica e passível de reflexão sociológica. Não diferente dos filmes, as músicas fazem um protesto frente às mazelas diárias enfrentadas pelo povo brasileiro, principalmente, os cidadãos que vivem nas favelas do Rio de Janeiro.

A trilha sonora de Tropa de Elite 1 e 2, reforçam a indignidade do povo brasileiro com a desfaçatez dos políticos e a arbitrariedade, muitas vezes cometida pela autoridade policial quando em contato com a população da periferia dos grandes centros urbanos. Nesse sentido, a música exerce o poder de protesto, que pela voz dos artistas leva até as comunidades carentes uma reflexão indireta, por meio da cultura de massa - as rádios, os CDs, a televisão, os DVDs, a internet, etc. O povo tem na música a oportunidade de dar voz aos seus problemas sociais, políticos e econômicos. A música acaba por torna-se um recurso poderoso e importante na cultura de um país com tantos problemas a resolver, como é o caso do Brasil. Porém, observamos em Adorno que:

Em vez de se limitar a cobrir a dor com o véu de uma solidariedade improvisada, a indústria cultural põe toda sua honra comercial em encará-la virilmente e em admiti-la mantendo com dificuldade a sua compostura. O pathos da compostura justifica o mundo que a torna necessária. Esta é a vida, assim dura, mas por isso assim também maravilhosa e sadia. A mentira não recua diante do trágico, a sociedade total não abole, mas registra e planifica a dor de seus membros; assim também procede a cultura de massa com o trágico (ADORNO, 2002, p.51).

É interessante notar que mesmo sabendo do perigo de expor os problemas sociais ao povo, a indústria cultural, por meio das músicas, disponibiliza 
comercialmente canções de protesto que poderão fazer as pessoas refletirem sobre as dificuldades vivenciadas diariamente. Mas, a ideologia do sistema é tão competente que a mentira sobre uma possível vida boa e feliz acaba prevalecendo e cegando uma possível revolução do pensamento e das ações da massa social. A sociedade, mesmo diante de músicas críticas, não consegue, ou não tem coragem de mudar o sistema.

As músicas dos dois filmes conseguem expor essas mazelas sociais, políticas e econômicas do povo brasileiro, mas não conseguiu causar uma comoção maciça, levando a uma mudança de valores na sociedade capitalista.

La cultura musical será entendida como el conjunto de procesos que en lo artístico, lo económico y lo social se interrelacionan para hacer posible la creación (producción), la circulación y el consumo masivo de la música, o sea: El, ciclo de la creación musical, el ciclo de la difusión musical, el sistema de producción y distribución de los bienes materiales musicales de consumo (RODRÍGUEZ, 2006, p.319).

Na pós-modernidade, o que fica visível é um consumismo descartável das mercadorias culturais - músicas, filmes, etc - ou seja, há uma sedução que aliena o corpo social, impulsionando a industrialização e consequentemente a produção de todo tipo de coisa na sociedade contemporânea.

\section{Trilha Sonora}

As letras das músicas nos apresentam um repertório rico em análises críticas sobre os problemas que afligem a sociedade em geral, particularmente enfatizando a complexidade da sociedade carioca. Os desafios sociais, políticos e econômicos do Rio de Janeiro são construídos em parte, nos dois filmes Tropa de Elite. Nesse caso, os filmes constroem uma realidade violenta que obriga milhares de pessoas a lutar pela sobrevivência em meio ao duelo entre crime organizado e poder estatal. Fenômenos que podemos observar nos trechos das músicas abaixo:

\section{Rap das Armas}

Mc Júnior \& Mc Leonardo

Revista Digital do LAV - Santa Maria - vol. 8, n. 3, p. 3 - 27. - set./dez. 2015 ISSN 1983 - 7348 http://dx.doi.org/10.5902/1983734818109 
Meu Brasil é um país tropical

A terra do funk, a terra do carnaval

o meu Rio de Janeiro é um cartão postal

Mas eu vou falar de um problema nacional

parapapapapapapapa

parapapapapapapapa

paparapaparapapara clak bumm

parapapapapapapapa

\section{O Calibre}

Os Paralamas do Sucesso

Eu vivo sem saber até quando ainda estou vivo

Sem saber o calibre do perigo

Eu não sei d'aonde vem o tiro

\section{Tribunal de Rua}

\section{O Rappa}

O cano do fuzil

Refletiu o lado ruim do Brasil

Nos olhos de quem quer

E quem me viu, único civil

Rodeado de soldados

Como seu eu fosse o culpado

No fundo querendo estar

A margem do seu pesadelo

Estar acima do biótipo suspeito

Nem que seja dentro de um carro importado

Com um salário suspeito

Endossando a impunidade

A procura de respeito 
Nas letras dessas músicas encontramos uma crítica social que enfatizam as armas de fogo, um dos principais objetos da violência nas favelas do Rio de Janeiro. Em Rap das Armas, observamos que a letra diz que o Brasil é a terra do funk e do carnaval, dando alusão a um país feliz por causa da alegria que sua música entoa. Mas, em seguida a letra esclarece que a realidade da sociedade brasileira é bem diferente, e a letra da música se complementa com um dos refrãos mais populares destacado nos filmes, e consequentemente nos bailes funk carioca.

O refrão "paparapaparapapara clak bumm" é uma referência ao som das armas de fogo (revolveres, metralhadoras, fuzis, etc), audível na rotina da maioria das favelas do Rio de Janeiro. Um potencial bélico que não está só nas mãos dos bandidos, mas também do poder estatal. Sobre essa questão Carvalho (2007, p.243) reforça para que "sejamos corajosos, e não covardes a ponto de nos apoiarmos nas armas de fogo como nossa única saída".

Nos filmes Tropa de Elite, o uso de armas de fogo é uma constante, típico recurso narrativo dos filmes policiais de ação hollywoodianos. E as músicas da trilha sonora dos dois filmes seguiram nesse contexto, explorando letras de funk, rock, pagode, samba e reggae, que destaca aquilo que é a realidade nas favelas da cidade carioca. Em Araújo (2005, p.202) observamos essa realidade musical nas favelas do Rio de Janeiro (em pesquisa na Maré), porém, notamos que há uma diversidade de estilos musicais como o forró e "a música apreciada por segmentos minoritários, como o pop africano ouvido pelos mais de mil angolanos moradores da região".

Nas músicas "O Calibre" e "Tribunal de Rua", há também ênfase nas armas de fogo. No rock do Paralamas do Sucesso, o calibre do perigo gera na população o medo de ser atingido por bala perdida - o cidadão sai de casa sem saber se voltará vivo por causa dos constantes tiroteios urbanos entre bandido-bandido e políciabandido. No caso da música "Tribunal de Rua", há destaque para o uso de armas pesadas, como o fuzil, que reflete o lado problemático do Brasil, mostrando inclusive o preconceito social experimentado pela maioria dos moradores de favela no Rio de Janeiro.

O poder estatal representado pelas ações da força policial, foi uma questão importante e muito polêmica levantada no filme Tropa de Elite 1 e 2. Observamos esse fenômeno nos trechos das músicas citadas abaixo:

\section{Tropa de Elite}

\section{Tihuana}

Revista Digital do LAV - Santa Maria - vol. 8, n. 3, p. 3 - 27. - set./dez. $2015 \quad$ ISSN 1983 - 7348 http://dx.doi.org/10.5902/1983734818109 
Tropa de elite, osso duro de roer

Pega um pega geral, também vai pegar você

Tropa de elite, osso duro de roer

Pega um pega geral, também vai pegar você

\section{Kátia Flávia}

Fausto Fawcett \& Os Robôs Efêmeros

Polícia!

Polícia Belford Roxo, de Duque de Caxias

Polícia Madureira, polícia Deodoro, São Cristóvão, Bonsucesso, da Benfica, da Pavuna, da Tijuca, de Quintino, do Catete, Grajaú,

Polícia pode vir! porque

Meu nome é Kátia Flávia, Godiva do Irajá, me escondi aqui em Copa

\section{Polícia}

Titãs

Dizem que ela existe

Prá ajudar!

Dizem que ela existe

Prá proteger!

Eu sei que ela pode

Te parar!

Eu sei que ela pode

Te prender!...

\section{Comboio do Terror}

Tihuana

Chegou o comboio do terror

Vacilou tu já rodou

Quero ver me segurar...

Revista Digital do LAV - Santa Maria - vol. 8, n. 3, p. 3 - 27. - set./dez. $2015 \quad$ ISSN 1983 - 7348 http://dx.doi.org/10.5902/1983734818109 
Essas músicas ressaltando as ações policiais são algumas das temáticas na trilha sonora dos dois filmes Tropa de Elite. A polêmica em torno dessa questão se desprendeu por visualizarmos cenas fortes de truculência policial nas favelas do Rio de Janeiro. Mas, o que enriqueceu os debates, foi o fato dos dois filmes ter colocado o dedo na ferida de uma burguesia hipócrita que sustenta a violência nas favelas do Rio de Janeiro - com o consumo de drogas leves e pesadas.

Esse fenômeno contemporâneo do uso de drogas pela burguesia, principalmente dentro das universidades públicas e privadas, trouxe ao debate as consequências desse ato numa sociedade cada vez mais armada, tanto a polícia, como os bandidos. O uso truculento da força policial contra traficantes de drogas nas favelas cariocas expõe a microfísica do poder existentes nos becos e vielas das áreas periféricas da cidade carioca. As músicas supracitadas demonstram em suas letras que a Tropa de Elite do BOPE é "osso duro de roer". Isso pode refletir que nas ações desenvolvidas os métodos não são nada convencionais - vide a música Comboio do Terror.

No filme a violência usada pela força estatal é considerada arbitrária e as músicas da trilha sonora legitimam esse poder despótico. Entretanto, na música Polícia, observamos um contraponto: "dizem que ela existe prá ajudar!; dizem que ela existe prá proteger!". Pensamos então na indagação de Soares (2007, p.240) "o que distingue bandidos e polícia, se a violência arbitrária é a linguagem comum que os identifica?".

Refletir sobre a trilha sonora de Tropa de Elite 1 e 2 é se deparar com questões complexas que envolvem a cidade do Rio de Janeiro. Com a segunda maior população do Brasil, a metrópole carioca tem em sua estrutura social problemas complexos, sobretudo aqueles ligados ao narcotráfico. Com milhares de pessoas vivendo em centenas de favelas, a busca por uma vida melhor é o sonho de muitos indivíduos que lutam para sobreviver. Nos trechos das músicas em destaque, observamos uma busca pela felicidade, por direitos iguais, por cidadania, liberdade e paz:

\section{Rap da Felicidade}

Mc Cidinho \& Mc Doca

Eu só quero é ser feliz

Andar tranqüilamente na favela onde eu nasci, é

Revista Digital do LAV - Santa Maria - vol. 8, n. 3, p. 3 - 27. - set./dez. 2015 ISSN 1983 - 7348 http://dx.doi.org/10.5902/1983734818109 
E poder me orgulhar

E ter a consciência que o pobre tem seu lugar

\section{Quem é Ela?}

Zeca Pagodinho

Se eu vou na Mangueira ela vai

Se eu vou na Portela ela está

Ela vai no Cacique de Ramos

Ela vai no Estácio de Sá

Ela vai no pagode em Xerém

Ela vai no pagode em Irajá...

\section{Tá Tudo Errado}

Mc Júnior \& Mc Leonardo

Comunidade que vive a vontade

Com mais liberdade tem mais pra colher

Pois alguns caminhos pra felicidade

São paz, cultura e lazer

Comunidade que vive acuada

Tomando porrada de todos os lados

Fica mais longe da tal esperança

Os menor vão crescendo tudo revoltado

Não se combate crime organizado

Mandando blindado pra beco e viela

Pois só vai gerar mais ira

Naqueles que moram dentro da favela

Sou favelado e exijo respeito

São só meus direitos que eu peço aqui

Pé na porta sem mandado

Tem que ser condenado

Não pode existir

\section{Zé Caroço}

Leci Brandão

Revista Digital do LAV - Santa Maria - vol. 8, n. 3, p. 3 - 27. - set./dez. $2015 \quad$ ISSN 1983 - 7348 http://dx.doi.org/10.5902/1983734818109 
Está nascendo um novo líder No morro do Pau da Bandeira Está nascendo um novo líder No morro do Pau da Bandeira No morro do Pau da Bandeira No morro do Pau da Bandeira

Essas letras não expressam somente o desejo de uma vida melhor, com direitos e cidadania garantidos pelo Estado. Mas, apesar de todas as dificuldades e mazelas sociais existentes nas favelas do Rio de Janeiro, há nas letras das músicas, uma consciência política e social de que o pobre tem os seus direitos e que o caminho da paz pode ser encontrado na cultura e no lazer, vide música "Tá Tudo Errado". Segundo Giovannetti (2001, p.73) esse fenômeno crítico nas letras das músicas ocorrem "en la medida en que la situación social empeoraba, el comentario social dentro de la música aumento".

Na música Rap da Felicidade, notamos que as pessoas da favela querem ser feliz e ter a tranquilidade de viver com segurança e orgulho no lugar onde nasceram. A consciência política e social verificamos na letra da música cantada por Leci Brandão, que destaca o nascimento de "um novo líder". E esse novo líder nasce no morro do Pau da Bandeira, uma favela carioca. A música vem renovar a esperança do povo em um novo líder político que traga o bem para a favela.

Em Quem é Ela?, o sambista Zeca Pagodinho um dos maiores ícones da música brasileira, especialmente no Rio de Janeiro, canta uma música sobre a mulher que frequenta as rodas de pagode nas favelas cariocas. Na letra da música notamos que o pagode nas favelas é também um ponto de encontro para paqueras e namoros, ou seja, um ambiente descontraído para reforçar as relações sociais, sejam elas intimistas ou apenas de bons amigos.

As favelas cariocas como temática central dos filmes de José Padilha, também acaba sendo foco principal para políticos em época de eleições no Brasil. E a trilha sonora dos filmes tocam nesse assunto como podemos perceber nas músicas "Que País é Esse?", "Cadidato Caô Caô", e "Brasil":

\section{Que País é Esse?}

\section{Legião Urbana}


Nas favelas, no Senado

Sujeira pra todo lado

Ninguém respeita a Constituição

Mas todos acreditam no futuro da nação

Que país é esse?

Que país é esse?

Que país é esse?

\section{Candidato Caô Caô}

Marcelo D2

Ele subiu o morro sem gravata

Dizendo que gostava da raça

Foi lá na tendinha

Bebeu cachaça

Até bagulho fumou

Foi no meu barracão

E lá usou

Lata de goiabada como prato

Eu logo percebi

É mais um candidato

Para a próxima eleição...

\section{Brasil}

Cazuza

Brasil!

Mostra tua cara

Quero ver quem paga

Pra gente ficar assim

Brasil!

Qual é o teu negócio?

O nome do teu sócio?

Confia em mim

Revista Digital do LAV - Santa Maria - vol. 8, n. 3, p. 3 - 27. - set./dez. $2015 \quad$ ISSN 1983 - 7348 http://dx.doi.org/10.5902/1983734818109 
Nos trechos das três músicas acima, notamos que o rock e o rap vão criticar um país que apresenta diversos problemas políticos, sociais, econômicos, éticos e morais, essencialmente em épocas de eleições governamentais, que fazem candidatos a cargos políticos assumirem uma caricatura onírica e delirante. Nesse sentido, Giovannetti (2001, p.79) destaca que "toda música es política por naturaleza".

As músicas selecionadas para a trilha sonora, expressam uma insatisfação com o sistema político brasileiro que manipula a massa social, usando máscaras para enganar o povo com promessas que não serão cumpridas nas "favelas e no senado", ficando assim, "sujeira pra todo lado".

No entanto, o Rio de Janeiro continua sendo a cidade maravilhosa, e como canta a música: "abençoada por Deus e bonita por natureza". Essa crença religiosa sobre a cidade carioca também verificamos na música Lado $B$ Lado $A$ :

\section{Lado B Lado A}

O Rappa

Se eles são Exu

Eu sou Iemanjá

Se eles matam o bicho

Eu tomo banho de mar

Com o corpo fechado

Ninguém vai me pegar

Lado A lado B

Lado B lado A...

Porém, nesse caso, a religiosidade está centrada nas crenças afro-brasileiras que destacam na música elementos de fé referentes aos orixás africanos. Os símbolos religiosos africanos caracterizam o poder de proteção que o homem das periferias dos grandes centros urbanos precisam para sobreviver. Salientamos que no caso do Rio de Janeiro, cidade construída nos filmes Tropa de Elite 1 e 2, há um grande contingente populacional afro-brasileiro, que culturalmente tem em si a fé na religiosidade afrodescendente. 
Embora a fé seja um fenômeno que traz esperança a sociedade, os preconceitos ainda são motivos de desconfiança na humanidade. Na música "Nossa Bandeira", podemos analisar que a letra é um convite á reflexão sobre os preconceitos sociais que milhares de pessoas pobres sofrem por fazer parte de uma classe social menos favorecida. A música em questão, interroga o ouvinte na busca de uma resposta sobre o que te faz ser um homem do bem ou do mal? O que te faz ser um doutor, ou um marginal? Nesse sentido, a música lança questionamentos sociológicos e filosóficos sobre a formação do homem na sociedade, e diversos fatores são passíveis de análises e interpretações.

\section{Nossa Bandeira}

Mc Júnior \& Mc Leonardo

Voltei pra defender nossa bandeira.

Levanta acampamento, guerreiro,

É hora de avançar.

Vamos falar de preconceito social,

O que te faz ser um "doutô"

E o que te faz ser marginal.

Vamos falar de preconceito social,

$\mathrm{O}$ que te faz homem do bem

E o que te faz homem do mal.

Por fim, a música "Brilhar a Minha Estrela" nos permite pensar sobre o instinto de sobrevivência dos indivíduos numa sociedade que apresenta diversos problemas sociais, econômicos e políticos, com índices elevados de criminalidade, corrupção, desemprego, além de um sistema capitalista que obriga as pessoas a lutarem diariamente por suas próprias vidas. Para Amaral (2007, p.229), "o sistema do capital pressupõe a sobrevivência em condições precárias da maior parte da população mundial".

\section{Brilhar a minha Estrela}

Sangue da Cidade 
O mais importante prum guerreiro

é simplesmente a vontade de viver, sem parar prá pensar nos momentos que virão.

Ele sabe o que quer, sabe o que é, conhece o caminho, é o dono da sua verdade,do seu destino.

As músicas selecionadas para a trilha sonora dos dois filmes reforçam o que o espectador visualiza na tela do cinema, da televisão ou do computador. Ouvir as músicas de Tropa de Elite 1 e 2, é ter a oportunidade de entrar em contato com uma trilha sonora crítica que aborda temas recorrentes a sociedade carioca, sobretudo aqueles presenciados diariamente pelos cidadãos moradores das favelas. Essas músicas apresentam fenômenos similares à música portorriquenha "Somos el son", que Rivera (1998, p.87) destacou como "la importancia del lenguaje musical em la expresión de las identidades y la nacionalidad".

A realidade social da cidade do Rio de Janeiro construída nos dois filmes, nos revelam um fenômeno complexo que envolve comunidades que abrigam famílias com suas crianças inocentes expostas a violência do crime organizado e a falta de escrúpulos de políticos corruptos. A esperança, já cantada em muitas músicas, pode estar no futuro das centenas de crianças que vivem nas favelas cariocas, porém ainda não encontramos solução para os antagonismos sociais existentes no Rio de Janeiro, que em contraponto com a música, continua sendo a: "cidade maravilhosa cheia de encantos mil".

\section{Imagem audiovisual}

O cinema há muito tempo deixou de ser um conjunto de imagens em movimento. Após a invenção do sistema sonoro no suporte cinematográfico, o som tornou-se algo indispensável aos filmes.

As manifestações audiovisuais são, também, o encontro de muitas vozes simultâneas, que se manifestam por vias muito diferentes: pela fala propriamente dita, pelos efeitos sonoros, pela música e pelas imagens em movimento. A partir daí, o

Revista Digital do LAV - Santa Maria - vol. 8, n. 3, p. 3 - 27. - set./dez. 2015 ISSN 1983 - 7348 http://dx.doi.org/10.5902/1983734818109 
paralelo com a polifonia musical parece ser não apenas possível, mas provável (CARRASCO, 2003, p.5-6).

Com isso, o cinema forma uma simbiose vantajosa com a música desempenhando um poder político e econômico, influenciado muitas culturas por meio das suas imagens audiovisuais.

Imagem 1: Cena filme Tropa de Elite 1.

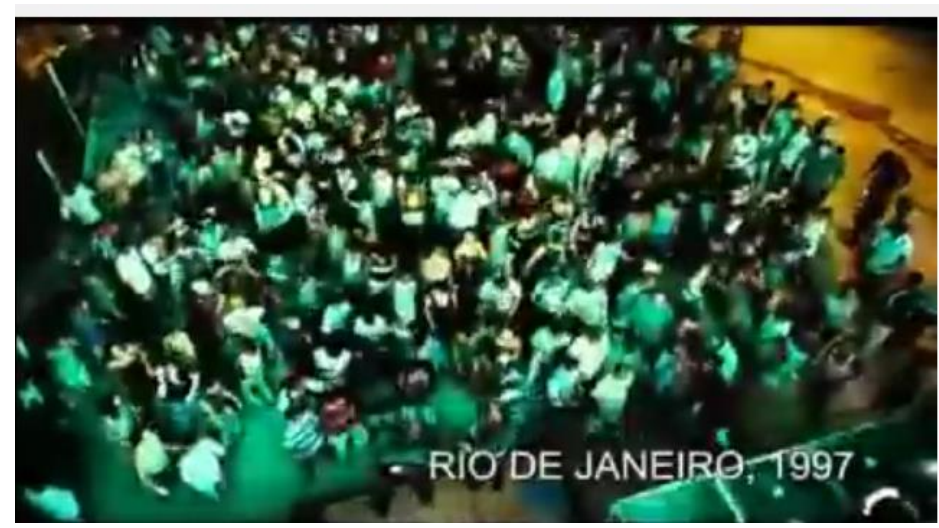

Fonte: DVD filme Tropa de Elite 1.

$\mathrm{Na}$ imagem 1, verificamos uma cena do primeiro filme Tropa de Elite, onde a trilha sonora inicia com a música Rap das Armas, tocada em um baile funk de uma favela carioca. Nessa cena observamos um grupo de pessoas da comunidade se divertindo ao som de uma música que tem em sua letra a representação sonora de armas de fogo quando estão sendo disparadas. Esse elemento sonoro oferece ao baile funk um refrão que faz parte da rotina de muitos moradores de favela no Rio de Janeiro.

O baile funk carioca representado no filme mostra uma realidade complexa que mistura música e felicidade com crime organizado. O contraditório nesse fenômeno social é a convivência diária com um potencial bélico digno de guerra, que ao mesmo tempo em que está inserido nos becos e vielas das favelas, também pode ser ouvido nas letras das músicas tocadas nos diversos aparelhos de som das casa de muitos moradores dessas favelas. A letra da música Rap das Armas parece não despertar a consciência crítica dessas pessoas que estão se divertindo no baile funk que Tropa de Elite 1 constrói com muito realismo.

Revista Digital do LAV - Santa Maria - vol. 8, n. 3, p. 3 - 27. - set./dez. 2015 ISSN 1983 - 7348 http://dx.doi.org/10.5902/1983734818109 
Imagem 2: Cena do filme Tropa de Elite 2.

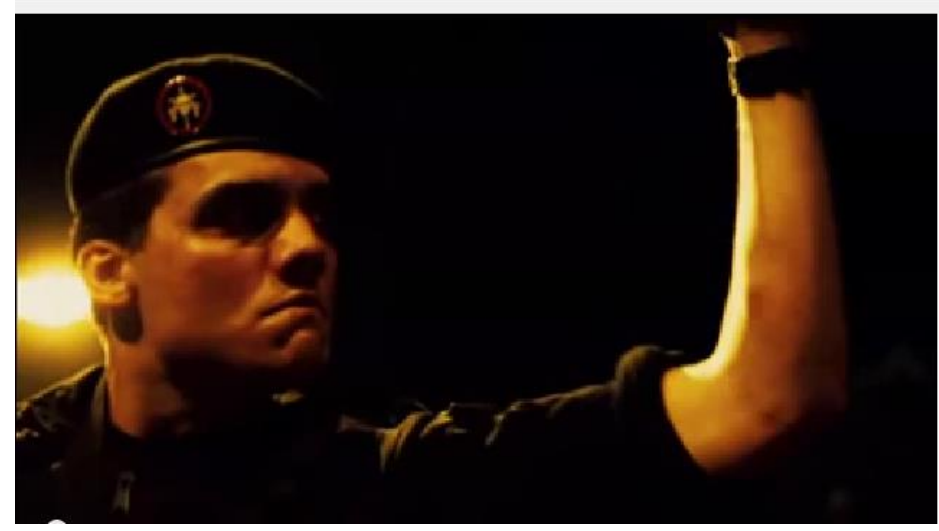

Fonte: DVD filme Tropa de Elite 2.

$\mathrm{Na}$ imagem 2, vemos o protagonista do filme, Capitão Nascimento (Wagner Moura), comandando mais uma missão numa favela do Rio de Janeiro. Essa cena faz parte de um clipe no começo do filme onde o nome do elenco e da produção é apresentado, e a primeira música da trilha é tocada.

No filme Tropa de Elite 2, notamos logo no início que a sonorização é composta por sons de uma arma de fogo sendo preparada para o uso. Em seguida visualizamos a imagem dessa arma de fogo sendo carregada com munições pesadas. Após uma breve introdução narrativa, a trilha sonora do filme se apresenta com o rock da banda Tihuana, que expressa em sua letra uma advertência sobre a tropa de elite do BOPE ("osso duro de roer"). Essa música que leva o mesmo nome do filme, fez muito sucesso no Brasil, sendo tocada e conhecida em âmbito nacional.

A imagem fílmica após a década de 1920, com o surgimento do cinema sonoro, alia-se aos recursos musicais e se potencializa tornando imagens audiovisuais que vão desempenhar um poder eficiente e lucrativo na indústria cultural fonográfica e cinematográfica.

\section{Música, cinema e cultura}

É inegável que a globalização revolucionou o mundo com possibilidades de integração entre os povos. Esse fenômeno uniu as sociedades de diversos países numa troca constante de informações e tecnologias criando dependências econômicas e processos de "transculturación", que segundo Pelinski (2000, p.177) são "procesos de desarraigamiento progresivo de una cultura y de creación de una 
cultura nueva a través del diálogo (generalmente conflictivo) y la negociación de la identidad primera con la diversidad de otras culturas".

Nesse caso, a trilha sonora dos filmes Tropa de Elite 1 e 2, se beneficiam dessas tecnologias e dos processos de aculturação e informações em tempo real para se difundirem na sociedade por meio das rádios, da internet, dos CDs e DVDs piratas e ilegais.

Em Ortiz (2003, p.31), observamos que "as tecnologias de comunicação, ao aproximarem as pessoas, tornaria o mundo cada vez menor e idêntico". Dentro desse contexto, a indústria fonográfica se expandiu mundialmente, partindo principalmente dos EUA, e se instalando em diversos países através de suas empresas multinacionais, com suas políticas culturais dominantes. Porém, esse fenômeno abriu precedentes para surgirem novas formas de acesso aos produtos culturais industrializados por essas corporações. O poder paralelo da pirataria, ou seja, a produção ilegal de cópias dos produtos originais é uma realidade existente nas sociedades mundializadas. No Brasil, os CDs e DVDs dos dois filmes Tropa de Elite, foram amplamente pirateados e vendidos no mercado ilegal.

É interessante observar que para ter acesso ao filme e consequentemente à trilha sonora do mesmo, um mercado paralelo é movimentado para distribuir esses produtos a uma população de baixa renda que não teria acesso a esse tipo de cultura, por não conseguir pagar seus altos preços. No caso de filmes e músicas, esse fenômeno da pirataria se potencializa por causa do desenvolvimento constante das tecnologias e da internet, que rompe fronteiras entre o legal e ilegal. Baixar músicas e filmes da internet se tornou um hábito corriqueiro globalizado.

No entanto, notamos que essas músicas disponíveis na internet, são em sua maioria padronizadas a uma estrutura musical desenvolvido pelas grandes corporações norte-americanas. Nesse caso, notamos que os estilos musicais norteamericano são detectáveis nas músicas de muitos outros países, sobretudo em países do hemisfério sul. No Brasil, esse fenômeno é facilmente detectável, porque importamos muita tecnologia e consequentemente alguns costumes do hemisfério norte. A música brasileira, especificamente após o movimento da Tropicália no final da década de 1960, faz uso desse arsenal tecnológico e instrumental para criar suas composições, que segundo Ortiz (2003, p.30) "o processo de mundialização é um fenômeno social total que permeia o conjunto das manifestações culturais".

As músicas da trilha sonora dos filmes Tropa de Elite foram objetos selecionados na sua maioria por ter conteúdo crítico, e posteriormente classificados como músicas de protesto que contestam um sistema político, econômico e social

Revista Digital do LAV - Santa Maria - vol. 8, n. 3, p. 3 - 27. - set./dez. $2015 \quad$ ISSN 1983 - 7348 http://dx.doi.org/10.5902/1983734818109 
opressor. Em contraponto a esse fenômeno cultural, as músicas dos filmes acabam também se tornando um objeto subversivo político e econômico, uma vez que suas letras possuem conteúdos complexos e polêmicos, e ao mesmo tempo tornou-se um dos produtos culturais mais pirateado do país, trazendo consequências financeiras e fiscais.

\section{Considerações finais}

Sabemos que a música exerce um poder econômico e cultural muito grande nas sociedades mundializadas. Com o advento da globalização e o fenômeno da internet, as músicas se tornaram objetos de diversão, sentimentos e protestos. Existe uma polifonia musical e textual que engloba os diferentes contextos culturais das sociedades contemporâneas, ao mesmo tempo em que movimenta economicamente a indústria de muitos países, em especial dos EUA.

De acordo com Carrasco (2003, p.06), "o cinema, por exemplo, desenvolveu uma polifonia própria, audiovisual, formada por muitas vozes: imagens e sons, tendo a música como uma das vozes dessa polifonia". Entretanto, possui no seu formato diversos outros elementos que com a inserção da música no mesmo suporte conseguiu atingir um grau superior em se tratando de uma obra de arte.

O cinema como obra de arte existente desde o século XIX e aperfeiçoada pela indústria hollywoodiana, descobre no uso das trilhas sonoras mais uma forma de poder e dominação cultural. As músicas de muitos filmes fazem tanto sucesso, quanto a própria imagem-movimento. E os filmes Tropa de Elite 1 e 2, conseguiram atingir esse sucesso cultural no Brasil e no mundo, resultando em uma mercadoria poderosa de difusão, de um caso específico, sobre uma realidade regional do Rio de Janeiro.

A trilha sonora dos dois filmes permanece no imaginário coletivo do povo brasileiro, facilmente identificável como a música de Tropa de Elite. Notamos também que na trilha sonora dos filmes há uma "fusão de linguagens musicais, a qual move as lutas diárias pela sobrevivência física e emocional" (ARAÚJO JÚNIOR, 2005, p.205). Concluímos que a música de cinema consegue desempenhar um poder social nos espectadores, que também são ouvintes, e que posteriormente ao filme, vão igualmente se tornar consumidores da sua trilha sonora. Portanto, o cinema e sua trilha sonora acabam se tornando um objeto múltiplo de consumismo da grande massa.

Revista Digital do LAV - Santa Maria - vol. 8, n. 3, p. 3 - 27. - set./dez. 2015 ISSN 1983 - 7348 http://dx.doi.org/10.5902/1983734818109 


\section{REFERÊNCIAS}

ADORNO, Theodor W. Indústria Cultural e Sociedade. São Paulo: Ed. Paz e Terra, 2002.

AMARAL, Pedro. Tropa de Elite. In: In: Sessão de cinema. Revista Comunicação \& Política - CEBELA, v.25, n03, p.227-244, 2007.

ARAÚJO JÚNIOR, Samuel M. Samba e coexistência; repensando a agenda de pesquisa etnomusicológica. In: Ana Maria Ochoa; Martha Tupinambá de Ulhoa. (Org.). Música popular na América Latina. 1ed.Porto Alegre: Editora da UFRGS, v. 1, p. 194-213, 2005.

CANCLINI, Néstor Garcia (org.). Iberoamérica 2002. Diagnóstico y propuestas para el desarrollo cultural. In: Industrias Culturales, diversidad cultural y desarrollo iberoamericano. México: OEI/ Santillana, 2002.

CARVALHO, Ilona S. Polícia: espelho da sociedade?. In: Sessão de cinema. Revista Comunicação \& Politica - CEBELA, v.25, n03, p.227-244, 2007.

CARRASCO, Ney. Sygkhronos - a formação da poética musical do cinema. São Paulo: Via Lettera - Fapesp, 2003.

GIOVANNETTI, Jorge L. La sociabilidad de La música reggae. In: Sonidos de Condena - sociabilidad, historia y política en la música reggae de Jamaica. México: Ed. Siglo XXI, p.70-91, 2001.

MARTINO, Guilherme. Trilhas sonoras: de Nosferatu a $\mathbf{O}$ senhor dos Anéis, 80 anos de música no cinema. Londrina: Eduel, 2008.

MÁXIMO, João. A música do cinema: os 100 primeiros anos. Rio de Janeiro: Rocco, vol.(1, 2), 2003.

ORTIZ, Renato. Mundialização e cultura. São Paulo: Brasiliense, 2003.

PELINSKI, Ramón. Diásporas del tango rioplatense. In: Invitación a La etnomusicología - quince fragmentos y um tango. Madrid: Ed. Akal, p.176-193, 2000.

RIVERA, Ángel G. Quintero. Salsa, sabor y control - sociologia de la música tropical. México/Espanha: Siglo Ventuno editores, p.87-181, 1998.

Cuerpo y cultura. Las músicas "mulatas" y la subversión del

baile. Madrid: Iberoamericana, 2009.

RODRÍGUEZ, Olavo A. Estado actual de la música Cubana - problemas y perspectivas. In: Pensamiento Musicológico.La Habana: Ed Letras Cubanas, 2006.

Revista Digital do LAV - Santa Maria - vol. 8, n. 3, p. 3 - 27. - set./dez. $2015 \quad$ ISSN 1983 - 7348 http://dx.doi.org/10.5902/1983734818109 
SANTAELLA, Lucia. Por que as comunicações e as artes estão convergindo? São Paulo: Paulus, 2005.

SOARES, Luiz E. Aplausos à violência?. In: Sessão de cinema. Revista Comunicação \& Política - CEBELA, v.25, n03, p.227-244, 2007.

TRIGUEIRO, Michelangelo G. S. Sociologia da tecnologia: bioprospecção e legitimação. São Paulo: Centauro, 2009.

\section{FILMES}

Tropa de Elite 1. Direção: José Padilha. Brasil. Universal, 2007, DVD (116min.), cor.

Tropa de Elite 2. Direção: José Padilha. Brasil. Vinny Filmes, 2010, DVD (115min.), cor.

\section{MÚSICAS}

Tropa de Elite 1. Trilha sonora: Pedro Bromfman. Brasil. EMI Music, 2007, CD.

Tropa de Elite 2. Trilha sonora: Pedro Bromfman. Brasil. EMI Music, 2010, CD.

\footnotetext{
${ }^{1}$ Sociólogo, mestrando em História da Arte na Universidade Federal de São Paulo UNIFESP, com bolsa da Fundação de Amparo à Pesquisa do Estado de São Paulo FAPESP. Pós-Graduado em Artes Visuais, Intermeios e Educação na UNICAMP, e PósGraduado em Estudios Culturales em CLACSO/Argentina.

e-mail: clebergom@hotmail.com / cleber.gomes@unifesp.br
} 